\title{
ОБСЕ и миротворчество: опыт и перспективы
}

\author{
Фред Таннер ${ }^{*}$
}

\section{Аннотация}

Специальная мониторинговая миссия в Украине (СМM) - одна из немногих историй успеха ОБСЕ за последние годы. Эта гражданская миссия обладает уникальной возможностью действовать в качестве квазимиротворческих сил в зонах повышенного риска в Донбассе, наблюдая за выполнением режима прекращения огня и содействуя диалогу и гуманитарной деятельности в интересах тех, кто живет в зоне конфликта. В истории ОБСЕ была еще только одна миссия по наблюдению за прекращением огня: Контрольная миссия в Косово (КМК). В данной статье для ОБСЕ Insights рассматривается опыт миротворческой деятельности ОБСЕ. Особое внимание при этом уделяется двум вышеупомянутым миссиям. Все миротворческие операции ОБСЕ до настоящего времени были гражданскими, и автор полагает, что и в будущем развертывание ОБСЕ военных миссий вряд ли будет возможным. В статье анализируются уроки миротворческой деятельности ОБСЕ и представлены рекомендации для будущих миссий ОБСЕ и других организаций, действующих в условиях повышенного риска.

Ключевые слова

ОБСЕ, миротворческие операции, Контрольная миссия в Косово, Специальная мониторинговая миссия в Украине, извлеченные уроки и наилучшие практики.

Для цитирования этой публикации: Таннер Ф. ОБСЕ и миротворчество: опыт и перспективы // ОБСЕ Insights 4/2021 - Баден-Баден: Номос, 2022. URL: https://doi.org/10.5771/97837489 11463-04

\section{Введение}

В данной статье рассматриваются уроки, извлеченные из гражданских миротворческих операций ОБСЕ в зонах повышенного риска ${ }^{1}$. Такие миссии являются неотъемлемой частью международной деятельности по предотвращению конфликтов, регулированию кризисов и миростроительству. По данным Стокгольмского международного института исследования проблем мира, в 2020 г. в мире были развернуты в общей сложности шестьдесят две миротворческие и миростроительные операции. Двадцать пять из них были развернуты ООН и шестнадцать - ОБСЕ 2 .

* Фред Таннер, Институт международных отношений и развития, Центр исследования конфликтов, развития и миростроительства, Женева, fred.tanner@graduateinstitute.ch. 
На первый взгляд может показаться, что многоаспектная миротворческая миссия ООН в Сомали имеет мало общего с операциями ОБСЕ на Западных Балканах или в Центральной Азии. Однако на самом деле большинство полевых миссий ОБСЕ можно отнести к тому, что Независимая группа высокого уровня ООН по операциям в пользу мира называет «миротворческими операциями», хотя миротворческие операции ОБСЕ и не предусматривают принятие «жестких» мер, в частности, по защите гражданского населения. Развертывание миссий ОБСЕ, в состав которых входили бы полицейские или вооруженные подразделения, по-прежнему маловероятно, несмотря на то, что такая возможность обсуждалась с тех пор как она была предусмотрена Хельсинкским документом $1992 \Gamma^{3}$.

Варианты развертывания военной операции ОБСЕ по поддержанию мира разрабатывались лишь однажды - созданной в 1995 г. Группой планирования высокого уровня (ГПВУ) в рамках посреднической миссии Минской группы по Нагорному Карабаху под эгидой ОБСЕ. В ожидании мирного соглашения между Арменией и Азербайджаном ГПВУ разработала четыре варианта, самый жесткий из которых предусматривал развертывание вооруженного контингента в составе нескольких пехотных батальонов общей численностью до 5000 военнослужащих. Однако обсуждение данного варианта миротворчества резко оборвалось в конце 2020 г., когда Азербайджан силой вернул свои территории, а Россия направила в регион национальный миротворческий контингент.

\section{Опыт миротворческой деятельности ОБСЕ}

Каковы политические и оперативные уроки, извлеченные из деятельности миссий ОБСЕ, и как они могут способствовать повышению эффективности, политической и оперативной дееспособности будущих миротворческих миссий? В последние двадцать пять лет ОБСЕ включала в мандат ряда полевых операций полицейские или связанные с военными вопросами компоненты. Правда, эти решения предполагали только направление в состав миссий отдельных прикомандированных лиц, а не развертывание военных подразделений. Военные наблюдатели были направлены в Молдову (с 1993 г.) и в Грузию (2008 г.), гражданские наблюдатели были развернуты на границе Грузии с Российской Федерацией (1999-2005 гг.), а гражданские полицейские советники были частью Инициативы по обеспечению безопасности на уровне сообществ в Кыргызстане (2010-2015 гг.).

Что касается миростроительства, то обучение и укрепление потенциала полиции, включая оказание содействия органам полиции, осуществлялось Миссией ОБСЕ в Хорватии, а также в рамках Инициативы по обеспечению безопасности на уровне сообществ в Кыргызстане. Миссия в Скопье, в состав которой входит отдел общественной безопасности и работы с населением, занимается вопросами подготовки, 
мониторинга и реформирования полиции, а также оказанием содействия полиции в борьбе с незаконным оборотом оружия и организованной преступностью 4 .

В то время как деятельность полевых операций ОБСЕ в Центральной Азии и на Западных Балканах была сосредоточена в основном на укреплении устойчивости обществ и надлежащего управления, миссии ОБСЕ в Боснии и Герцеговине, Косово и Северной Македонии были нацелены на содействие выполнению мирных соглашений и (или) резолюций ООН, направленных на предотвращение и урегулирование конфликтов.

\section{Миссии ОБСЕ по наблюдению за соблюдением режима прекращения огня}

Из всех развертывавшихся до настоящего времени миссий ОБСЕ только две можно сравнить с миротворческими операциями военного типа: Контрольную миссию в Косово (КМК) и Специальную мониторинговую миссию в Украине (СММ). Обе гражданские миссии по наблюдению за прекращением огня развертывались в условиях относительного спокойствия, но оказались в зоне повышенного риска, где не было мира, который нужно было поддерживать. КМК была развернута в Югославии в условиях нараставшего в 1998 г. кризиса в Косово, когда здесь совершались жестокие преступления, а США и НАТО угрожали применить силу против режима Милошевича. Мандат КМК, согласованный без участия ОБСЕ в результате переговоров Р. Холбрука и С. Милошевича, требовал от обеих сторон прекратить зверства, вывести вооруженные силы из Косово и соблюдать режим прекращения огня. Предполагалось, что КМК будет примерно вдвое больше нынешней СММ, но она не успела нарастить свое присутствие настолько быстро, чтобы справиться с растущими угрозами для безопасности. В марте 1999 г., через шесть месяцев после начала развертывания по соображениям безопасности она была эвакуирована в соседнюю Бывшую Югославскую Республику Македония (Северная Македония) после чего ее деятельность была прекращена.

СММ планировалась в начале 2014 г. как операция по превентивному развертыванию, направленная на деэскалацию, укрепление доверия и содействие диалогу на всей территории Украины. Через несколько недель миссия оказалась на передовой линии вооруженного конфликта и была вынуждена адаптироваться к новым условиям безопасности и новым задачам по контролю за прекращением огня в соответствии с Минскими соглашениями. С тех пор СММ стала важным, охватывающим широкий спектр деятельности инструментом ОБСЕ по урегулированию кризиса в Украине.

Ниже мы рассмотрим шесть характеристик этих двух миссий, уделяя особое внимание СММ, чтобы выявить уроки и наилучшие практики в их деятельности и 
сформулировать рекомендации для будущих миссий ОБСЕ и других региональных и международных миссий, действующих на основе мандата ООН.

\section{Мандат миссии}

Мандат КМК был сформулирован без участия ОБСЕ. Это привело к несогласованности между политическим процессом, с одной стороны, и оперативным планированием и стратегическим надзором - с другой. Миссия имела чрезмерно широкий мандат, включая мониторинг соблюдения режима прекращения огня, расследование нарушений, содействие возвращению перемещенных лиц, мониторинг эффективности государственного управления и наблюдение за выборами. В сочетании с организационными проблемами это не позволило руководству КМК разработать последовательный план действий ${ }^{5}$.

В отличие от этого, мандат СММ был разработан в 2014 г. Председателем ОБСЕ в сотрудничестве с государствами-участниками во время кризиса на Майдане. Он был одобрен на основе консенсуса, несмотря на крайне напряженный политический климат, и пользуется поддержкой до сегодняшнего дня 6 . Широта мандата обеспечила гибкость в том, что касается географического охвата миссии. Это было крайне важно, учитывая незаконную аннексию Крыма Россией. Однако мандат не лишен недостатков. В некоторых областях, таких как содействие диалогу, более директивные формулировки обеспечили бы дополнительный синергетический эффект с другими инициативами ОБСЕ в Украине. К недостаткам можно отнести и отсутствие каких-либо ссылок на необходимость учитывать в деятельности миссии гендерные аспекты.

Гибкость мандата позволила СММ оперативно реагировать на развитие конфликта и меняющуюся обстановку. Хотя он остается неизменным с 2014 г., Трехсторонней контактной группой (ТКГ) и Нормандской группой перед миссией ставились новые задачи. Как следует из доклада ОБСЕ «Мирное присутствие», возможности организации и СММ по планированию деятельности по-прежнему весьма ограничены. В условиях чрезвычайных ситуаций возрастает опасность ограничиться принятием лишь временных мер по реагированию на них, а возможности или пространство для долгосрочного планирования и разработки стратегии ограничены ${ }^{7}$.

\section{Параметры развертывания}

И КМК, и СММ столкнулись с парадоксом: гражданским миротворческим миссиям приходилось решать поставленные перед ними задачи в условиях военных вызовов $^{8}$. На коротком этапе планирования КМК в 1998 г. исполнительные структуры 
ОБСЕ не смогли дать четких указаний по выполнению мандата. Более того, процесс набора персонала (в основном прикомандированных специалистов по мониторингу соблюдения режима прекращения огня и охраны правопорядка) шел медленно, несмотря на обращение ООН ко всем государствам-участникам ОБСЕ ${ }^{9}$. Через три месяца на местах были развернуты 700 наблюдателей, а к марту 1999 г., когда миссия завершила свою деятельность по соображениям безопасности, их число возросло до 1400. С самого начала КМК не имела необходимой институциональной поддержки для ускоренного «формирования сил» и обеспечения безопасности персонала, необходимого для такой амбициозной полевой операции в условиях активного конфликта.

В отличие от этого, СММ ОБСЕ с самого начала могла полагаться на институциональную поддержку со стороны секретариата ОБСЕ и, в частности, Центра ОБСЕ по предотвращению конфликтов (ЦПК), что помогло ей постоянно адаптировать свою деятельность, наладить кадровое обеспечение и приобретение активов. Благодаря урокам, извлеченным из миссии КМК, и полномочиям, предоставленным решением Совета министров № 3/11 об элементах конфликтного цикла ${ }^{10}$, СММ могла полагаться на уже существующие:

- оперативную структуру реагирования на кризисные ситуации и персонал;

- $\quad$ реестр быстрого развертывания;

- виртуальный пул оборудования ${ }^{11}$.

\section{Беспристрастность в отчетности и деятельности}

Беспристрастность является ключевым требованием для любой миротворческой миссии наряду с консенсусом и неприменением силы. В конце 1990-х гг. ОБСЕ оказалась втянутой в силовое противостояние режима Милошевича с США, поддерживавшимися Советом Безопасности ООН и НАТО. Соглашение о развертывании миссии ОБСЕ было частью договоренности, которая включала также воздушное патрулирование НАТО в Югославии. Помимо этого безопасность КМК зависела от сил НАТО по эвакуации, размещенных в соседней БЮРМ 12 . С назначением американского дипломата У. Уокера главой миссии ОБСЕ не могла сохранить свой беспристрастный и нейтральный характер, поскольку США явно выступали в качестве противника режима Милошевича. Это стало очевидным, когда глава миссии был объявлен принимающим государством персоной нон грата ${ }^{13}$.

CMM, напротив, была учреждена не в результате балансирования на грани войны и смогла сохранить свою беспристрастность. Хотя СММ иногда подвергалась за это критике, в отличие от практики ООН она проводит «политику отказа от атрибуции», т.е. «сообщает факты, не возлагая на кого-либо вину, и соблюдает баланс между вопросами жесткой безопасности и гуманитарными, политическими и 
социально-экономическими последствиями конфликта» ${ }^{14}$. Тем не менее предпринимались настойчивые попытки оказать политическое влияние на миссию, в том числе со стороны постоянных представительств государств-участников ОБСЕ, будь то в отношении вопросов, касающихся обязанности соблюдать осторожность или атрибуции ответственности за нарушения режима прекращения огня.

\section{Использование передовых технологий в качестве мультипликатора потенциала}

В то время как КМК была «низкотехнологичной» миссией, СММ в результате политического давления со стороны Председателя ОБСЕ получила в свое распоряжение передовые технологии, включая камеры наблюдения, спутниковые снимки, акустические датчики и беспилотные летательные аппараты (БПЛА), которые дополняют информацию, собираемую наземными патрульными группами. Использование таких технологий в рамках СММ было санкционировано Минскими соглашениями о прекращении огня. Однако у ОБСЕ не было опыта закупки или использования БПЛА, и в итоге она заключила соглашение «под ключ» с частной компанией об аутсорсинге технических и экспертных услуг под контролем $\mathrm{CMM}^{15}$.

Использование БПЛА стало «мультипликатором силы» для миссии, поскольку позволило ей решать задачи, которые в противном случае решали бы патрульные группы в опасных или запретных зонах. Дистанционный мониторинг сыграл важную роль во время пандемии COVID-19, которая могла быть использована для блокирования патрульных групп в условиях локдауна, отказа в доступе и закрытия «границ».

Эксплуатация БПЛА в зонах активных конфликтов рискованна и дорогостояща, поскольку многие из них глушатся и обстреливаются, что является грубым нарушением Минских соглашений. С момента первого полета БПЛА в октябре 2014 г. по 31 марта 2019 г. СММ потеряла тридцать девять БПЛА. Из них 67\% были потеряны в неподконтрольных правительству районах, 31\% - в зоне, контролируемой правительством, и 2\% - на линии соприкосновения ${ }^{16}$.

С расширением применения передовых технологий возникли проблемы, связанные с обработкой и использованием потока получаемых данных. СММ оказалась плохо оснащенной для обработки больших объемов информации из разных источников. Кроме того, доступ наблюдателей к снимкам со спутников и БПЛА часто занимал слишком много времени, чтобы быть эффективным при планировании и осуществлении патрулирования. Необходимо было создать новую систему обработки информации, объединения данных, принятия решений, планирования и публичной отчетности ${ }^{17}$. 


\section{Правосубъектность и обязанность обеспечить безопасность персонала}

Отсутствие у ОБСЕ правосубъектности представляет собой серьезное препятствие для любой полевой миссии организации. СММ не могла планово наращивать свое присутствие на местах пока не был подписан меморандум о взаимопонимании с правительством принимающей страны. Это произошло через несколько недель после начала работы миссии ${ }^{18}$. Хуже того, в течение первых недель, не имея правовой защиты в Украине, ОБСЕ несла ответственность за любые ранения, полученные персоналом. В этот период восемь наблюдателей были взяты в заложники бандой казаков. В этой связи встал вопрос о том, кто будет нести ответственность в случае причинения им вреда: глава миссии, Генеральный секретарь, Председатель ОБСЕ, командирующие государства-участники? Такие вопросы, связанные с обязанностью обеспечить безопасность персонала, до сих пор не решены ${ }^{19}$. Еще одним ключевым недостатком СММ является отсутствие силовой защиты и зависимость от гарантий безопасности воюющих сторон. В отличие от КМК, в составе СММ нет специальных военных подразделений, которые могли бы решать задачи эвакуации персонала в случае необходимости. Сложная обстановка в зоне конфликта требует, чтобы подготовка к выполнению обязанностей по обеспечению безопасности шла параллельно с планированием миссии. К сожалению, это не было сделано при развертывании ни одной из миротворческих миссий ОБСЕ. В случае с КМК, например, призывы ОБСЕ о предоставлении мобильной медицинской помощи, включая медицинские и бронированные автомобили, оставались без ответа в течение нескольких месяцев после развертывания миссии ${ }^{20}$.

\section{Партнерства для совместных или «гибридных» миссий}

На сегодняшний день ни одна миссия ОБСЕ не проводилась в тандеме с миссиями других организаций. Стамбульская Хартия европейской безопасности 1999 г. позволила ОБСЕ работать совместно с другими региональными и международными организациями, в том числе в сфере миротворчества ${ }^{21}$. Предложение о «гибридной» или «расширенной» СММ появилось в 2014 г., когда Германия, Франция, Италия и Российская Федерация предложили миссии использовать БПЛА вместе с подразделениями военной поддержки. Эти предложения предполагали развертывание военных сил по защите. Однако включение национальных военных подразделений в состав СММ потенциально лишило бы ее гражданского характера и беспристрастности. К тому же для этого потребовалось бы принять дополнительное решение Постоянного совета и подписать двустороннее соглашение о статусе сил с Украиной ${ }^{22}$.

Еще одно предложение о гибридной операции, опять же в Украине, поступило от России в 2017 г., когда она представила проект резолюции Совета Безопасности 
ООН, в котором предлагалось создать легковооруженные миротворческие силы ООН для защиты СММ вдоль линии разграничения ${ }^{23}$. Украина отклонила вариант гибридной миссии ООН-ОБСЕ и, в свою очередь, предложила на сессии Генеральной Ассамблеи ООН 2017 г. провести военную операцию в рамках главы VII Устава $\mathrm{OOH} \mathrm{-} \mathrm{вариант,} \mathrm{который} \mathrm{сделал} \mathrm{бы} \mathrm{СММ} \mathrm{ненужной}{ }^{24}$. Оба предложения не получили достаточную поддержку и были отложены.

\section{Как можно использовать опыт и достижения СММ}

С момента своего развертывания в 2014 г. СММ доказала, что способна быстро извлекать уроки из своей деятельности. Несмотря на постоянные нарушения режима прекращения огня, отказ в доступе и пандемию COVID-19, она продолжала работать по обе стороны линии соприкосновения, хотя иногда с серьезными ограничениями. За прошедшие годы исследователи и практики изучали деятельность миссии и извлекли из нее определенные уроки ${ }^{25}$.

Учитывая обнадеживающий пример СMM, вполне возможно, что государстваучастники согласятся на проведение аналогичной миссии в другом месте, если этого потребуют изменения в региональной безопасности и политике. Наиболее очевидным выбором была бы операция в Нагорном Карабахе. Правда, сопредседатели Минской группы и ГПВУ оказались в стороне в условиях развертывания российских миротворческих сил. Тем не менее, как утверждает одна группа экспертов, потребность в многонациональных миротворческих силах ОБСЕ еще может появиться, «поскольку со временем Москва может не захотеть нести расходы и бремя, которые она сейчас несет в одиночку» ${ }^{26}$. В зависимости от политических событий и в рамках более широкой архитектуры возможное урегулирование может потребовать учреждения комплексной гражданской миротворческой миссии ОБСЕ для мониторинга соблюдения обязательств и содействия миростроительной деятельности.

\section{Заключение и рекомендации}

Гражданские операции решают ограниченные задачи, что выгодно отличает их от классических военных операций ООН по поддержанию мира. Поскольку их деятельность носит не силовой, а посреднический характер, мандат таких миссий легче согласовать на основе политического консенсуса, они более приемлемы для принимающего государства, им проще сохранять беспристрастность. Ключевое значение имеет достижение и сохранение совместной политической и оперативной 
ответственности за выполнение мандата, сохраняя при этом возможность «усилить» миссию, если она будет действовать в зоне вооруженного конфликта 27.

Мандат и дополнительные задачи СММ выходят далеко за рамки мониторинга соблюдения режима прекращения огня и включают мониторинг и подготовку докладов о нарушениях прав человека и экологической безопасности, а также оказание добрых услуг и содействие посредничеству ${ }^{28}$. Приверженность ОБСЕ такому всеобъемлющему подходу является ее преимуществом. Сегодня от миротворческих миссий все чаще требуется решать вопросы, связанные с нестабильностью, неустойчивостью и управлением на всех этапах конфликтного цикла.

Как показывают современные геополитические тенденции, миротворческие операции как инструменты предотвращения конфликтов и регулирования кризисов будут востребованы еще долгие годы. При планировании таких операций (или других возможных миссий ОБСЕ), принимая во внимание извлеченные уроки и наилучшие практики предыдущих миссий (особенно СММ), необходимо учитывать следующие рекомендации:

- Разработать гибкий мандат миссии. Мандат миссии должен быть директивным только в тех вопросах, решение которых нуждается в руководящих указаниях. Хороший мандат полевой миссии будет способствовать надлежащему планированию и разработке стратегии руководством миссии. Компромисс и консенсус в отношении мандата могут быть достигнуты посредством интерпретирующих заявлений, как это было в случае с СММ. Неотъемлемой частью мандата должна быть прямая ссылка на необходимость соблюдать гендерный паритет и учитывать гендерную проблематику.

- Обеспечить надежную институциональную поддержку для развертывания миссии. Неспособность КМК быстро задействовать экспертов с нужными навыками высветила важность надежной институциональной поддержки для развертывания миссии. Однако быстрое направление в состав миссии квалифицированного гражданского персонала с военным опытом зависит в большей степени от командирующих сотрудников государств, а не от ОБСЕ. Реестры быстрого развертывания и новые внутренние стандартные операционные процедуры (СОП) секретариата помогают эффективно действовать в ситуациях срочного реагирования ${ }^{29}$. Усиленная группа планирования в секретариате может способствовать более высокой готовности и лучшему планированию миссии не только для возможного развертывания в Нагорном Карабахе, но и других миссий. Стоит изучить вопрос о том, насколько тесно ГПВУ может быть связана с работой ЦПК, что позволило бы расширить возможности планирования в секретариате по всему спектру миссий.

- Сохранять беспристрастность. Гражданство главы миссии имеет значение. Руководство по отчетности должно включать СОП «без атрибуции». ОБСЕ следует разработать руководство по взаимодействию с непризнанными акторами на ос- 
нове документа ОБСЕ 1993 г. «Меры стабилизации в отношении локальных кризисных ситуаций» ${ }^{30}$.

- Использовать передовые технологии. Использование технических средств наблюдения стало отличительной чертой СММ. Дистанционный мониторинг позволяет избегать зон повышенной опасности и недружественных контрольно-пропускных пунктов. В сочетании с усовершенствованной обработкой данных и оперативным планированием он может сделать миссии более эффективными и безопасными. Платформы для обработки данных и соответствующий опыт должны быть доступны с самого начала. Полевые миссии ОБСЕ могут извлечь уроки из опыта СMM, используя передовые технологии для решения других задач, таких как управление рисками, связанными со стихийными бедствиями.

- Обязанность обеспечить безопасность персонала должна учитываться одновременно с планированием миссии. Для любой гражданской полевой миссии, действующей в условиях повышенного риска, с самого начала должны быть разработаны стратегия обеспечения безопасности и надлежащие меры надзора.

- Учитывать риски совместных миссий. Миссии, проводимые совместно с другими организациями, осуществимы, но политически сложны. «Гибридные» механизмы с полицейскими или военными контингентами потребуют от ОБСЕ больших затрат на планирование и могут поставить под угрозу беспристрастность ОБСЕ. Кроме того, необходимым условием развертывания таких миссий является принятие соответствующей резолюции Совета безопасности ООН.

- Поддерживать тесную согласованность политического процесса и оперативной деятельности. Судьба КМК показала, что руководству полевых операций крайне важно иметь доступ к политическому процессу. Это позволит избежать дробления полномочий, а такой риск всегда присутствует при проведении сложных операций. В случае СММ этот вопрос был решен путем предоставления главному наблюдателю миссии места за столом переговоров в рамках Минского процесса (в качестве координатора рабочей группы по безопасности ТКГ).

- Повышать осведомленность о преимуществах ОБСЕ и ее деятельности. Учитывая свой богатый опыт, ОБСЕ следует вкладывать больше средств как в процесс институционального обучения, так и в информационно-просветительскую деятельность. Важно укрепить доверие и уверенность государств-участников и международных организаций в способности ОБСЕ регулировать кризисы и проводить миротворческие операции даже в регионах повышенного риска.

\section{Примечания}

1 Термин «миротворческие операции» охватывает понятия миротворчества, миротворческих миссий, специальных политических миссий и полевых операций. В литературе тер- 
мины «миротворчество» и «миротворческие миссии» часто используются как взаимозаменяемые.

2 См.: Multilateral peace operations // Stockholm International Peace Research Institute, 2020. URL: https://www.sipri.org/sites/default/files/2020-06/mpo20_fill.pdf.

3 Глава III Хельсинкского документа (1992) остается нормативной основой для возможной деятельности ОБСЕ в области миротворчества. См.: Хельсинкский документ 1992 года. Вызов времени перемен. - Хельсинки, 1992. URL: https:/www.osce.org/ru/mc/39534.

Подробнее о текущих полевых операциях ОБСЕ см.: Survey of OSCE Field Operations. SEC.GAL/118/21. 13 September 2021 // Официальный сайт ОБCE. URL: https://www.osce.or $\mathrm{g} /$ secretariat $/ 74783$.

См.: Bellamy A. J., Griffin S. OSCE Peacekeeping: Lessons from the Kosovo Verification Mission // European Security. 2002. No 1. Р. 22.

6 Сначала мандат миссии продлевался каждые 6 месяцев. Затем вплоть до настоящего времени продление осуществлялось на ежегодной основе.

7 Cм.: A peaceful presence - the first five years of the OSCE Special Monitoring Mission to Ukraine // Официальный сайт ОБСЕ. 2021. 29 June. URL: https://www.osce.org/secretariat/49 1220.

8 Это включает в себя мониторинг прекращения огня; расследование нарушений режима прекращения огня; содействие, проверку и мониторинг отвода тяжелых вооружений; переговоры о локальных прекращениях огня на передовой («окна тишины»); и поддержание связи с военными координационными структурами.

9 Параграф 7 Резолюции Совета Безопасности ООН 1203 (1988): ООН «настоятельно призывает государства и международные организации предоставить персонал для Контрольной миссии ОБСЕ в Косово». См.: Резолюция 1203 (1998). S_RES_1203(1998)-RU). 24 октября 1998 // Официальный сайт OOH. URL: https://digitallibrary.un.org/record/262334?ln $=$ en.

10 См.: Совет министров ОБСЕ. Решение № 3/11 об элементах конфликтного цикла. 7 декабря 2011 // Официальный сайт ОБСЕ. URL: https://www.osce.org/files/f/documents/c/7/86625. pdf.

11 См.: Райт М. Решая проблемы конфликтного цикла - развивающийся инструментарий ОБСЕ // ОБСЕ Insights 3. - Баден-Баден: Номос, 2021. URL: https://doi.org/10.5771/9783748 921264-03.

12 См.: NATO Press Statement. (98)139. 5 December 1998 // Официальный сайт HATO. URL: https://www.nato.int/docu/pr/1998/p98-139e.htm.

13 Cм.: OSCE Chairmanship: Head of Kosovo Verification Mission declared 'persona non grata' // Официальный сайт ОБСЕ. 1999. 19 January. URL: https://www.osce.org/cio/52376.

14 A peaceful presence - the first five years of the OSCE Special Monitoring Mission to Ukraine. P. 67.

15 Оно включало пакетное соглашение с частной компанией, которая на начальном этапе предоставила две наземные станции управления, четыре БПЛА дальнего радиуса действия, шесть операторов и три человека обслуживающего персонала. См.: OSCE. Цит. раб. (ссылка 7). Р. 49.

16 A peaceful presence - the first five years of the OSCE Special Monitoring Mission to Ukraine. Р. 50.

17 Внедрение так называемой «корпоративной географической информационной системы» затянулось.

18 Отсутствие правосубъектности затрудняло закупки и ввоз в Украину необходимых для миссии предметов, не позволяло открывать банковские счета, заключать контракты и импортировать необходимое оборудование. См.: A peaceful presence - the first five years of the OSCE Special Monitoring Mission to Ukraine. P. 20. 
19 С тех пор как наблюдатели СММ впервые столкнулись с угрозой получения ранений, была проделана большая работа по решению вопросов, связанных с обязанностью по обеспечению безопасности персонала миссий ОБСЕ. См.: Merkelbach M. Voluntary guideline on the duty of care to seconded civilian personnel. - Swiss Federal Department of Foreign Affairs. Stabilisation Unit and Center for International Peace Operations, 2017. URL: https://www.eda.ad $\mathrm{min} . \mathrm{ch} / \mathrm{dam} / \mathrm{eda} / \mathrm{en} /$ documents/aussenpolitik/menschenrechte-menschliche-sicherheit/Voluntary Guidelines_on_the_Duty_of_Care_to_Seconded_Civilian_Personnel_Final_170420.pdf.

20 См.: Meier L. D. A role for OSCE peacekeeping? From the 1992 Helsinki Guidelines to the Special Monitoring Mission to Ukraine. CORE Working Paper 27. - Hamburg, 2015. P. 33. URL: https://ifsh.de/file-CORE/documents/Working_Papers/CORE_WP27.pdf.

21 См.: ОБСЕ. Стамбульский документ 1999 года (Хартия европейской безопасности и Декларация Стамбульской встречи на высшем уровне). PCORW389. Стамбул, 1999 // Официальный сайт ОБСЕ. URL: https://www.osce.org/ru/mc/39573.

22 Германия, например, предложила направить контингент со взводом разведывательных беспилотников LUNA. C учетом логистических, медицинских и других элементов контингент состоял бы из более чем 200 вооруженных солдат.

23 См.: Can peacekeepers break the deadlock in Ukraine? International Crisis Group, Europe Report No 246. 2017. 15 December. P. 2. URL: https://d2071andvip0wj.cloudfront.net/246-can -peacekeepers-break-the-deadlock-in-ukraine.pdf.

24 См.: Tanner F. Sustaining civilian missions in conflict zones: The case of the OSCE Special Monitoring Mission to Ukraine. Swisspeace Policy Brief. 2018. № 3. P. 2. URL: https://www.sw isspeace.ch/assets/publications/downloads/Policy-Briefs/6656f90042/Sustaining-Civilian-Missio ns-in-Conflict-Zones-Policy-Brief-18-swisspeace-fred_tanner.pdf.

25 См., например: Кемп У. Гражданские лица в зоне военных действий: ОБСЕ в Восточной Украине // Ежегодник ОБСЕ 2017: Ежегодник по вопросам Организации по безопасности и сотрудничеству в Европе. - Гамбург: [Институт исследования проблем мира и политики безопасности], 2020. - C. 175-192; Härtel A., Pisarenko A., Umland A. The OSCE's Special Monitoring Mission to Ukraine: The SMM's Work in the Donbas and Its Ukrainian Critique in 2014-2019 // Security and Human Rights. 2021. June. P. 1-34; A peaceful presence - the first five years of the OSCE Special Monitoring Mission to Ukraine.

26 Global Europe Program Working Group on the Future of the OSCE. Uncommon cause: The future of the OSCE. The Wilson Center, February 2021. P. 7. URL: https://www.wilsoncenter. org/sites/default/files/media/uploads/documents/Uncommon Cause - The Future of the OSCE v2.pdf.

27 Меры по усилению включают приоритет военных навыков при наборе персонала, специальную подготовку, возможности медицинской эвакуации, вооруженные автомобили с GPS, бронежилеты и шлемы, спутниковую связь в масштабах всей миссии и т.д. См.: Meier L. D. Op. cit. P. 46.

28 См.: A peaceful presence - the first five years of the OSCE Special Monitoring Mission to Ukraine . P. 17.

29 См.: Raith M. Op. cit. P. 48.

30 Меры стабилизации в отношении локальных кризисных ситуаций. DOC.FSC/2/96. 25 ноября 1993 // Официальный сайт ОБСЕ. URL: https://www.osce.org/ru/fsc/41320. 